\title{
El archivo señorial de Paracuellos, un fondo documental de los marqueses de Malagón
}

\section{The seigneurial archive of Paracuellos, a documentary collection of the Marquises of Malagón}

\author{
Antonio SÁnCHEZ GonZÁlez \\ Universidad de Huelva \\ antonio.sanchez@dhis2.uhu.es \\ http://orcid.org/0000-0001-5025-455X
}

Fecha de recepción: 09-06-2020

Fecha de aceptación: 29-09-2020

\section{RESUMEN}

Los Pardo-Tavera, mariscales de Castilla en la Edad Moderna, compraron a la Corona dos antiguas encomiendas militares a mediados del siglo XVI que se convirtieron en señoríos estables, caso de Paracuellos de Jarama y Malagón, este último convertido en marquesado en 1599.

Más tarde, los señores de Paracuellos y marqueses de Malagón entroncaron, a partir del siglo XVII, con otras casas nobiliarias peninsulares, pasando sus archivos a incorporarse sucesivamente, primero en el siglo XVIII, al de los duques de Santisteban del Puerto y, definitivamente en 1818, al de los duques de Medinaceli.

El objetivo de este artículo es dar a conocer el archivo de los señores de Paracuellos, desde su formación hasta nuestros días, tratando de sus escrituras, de su organización documental y su disposición actual, para facilitar el camino a futuras investigaciones sobre estos fondos.

Para ello, metodológicamente, no solo hemos trabajado en el fondo documental conservado en el Archivo Ducal de Medinaceli aquí objeto de estudio, revisando sus inventarios y analizando las marcas dorsales de cada pieza documental, sino también en la documentación de referencia que se conserva en otros archivos.

Palabras clave: mariscales de Castilla, marqueses de Malagón, archivo familiar, documentación señorial, familia Pardo-Tavera.

Topónimos: Paracuellos de Jarama

Periodo: siglos XII-XIX.

\section{ABSTRACT}

The Pardo-Tavera family, marshals of Castile during the Modern Age, purchased two military encomiendas in the middle of the $16^{\text {th }}$ century and transformed these into long-term lordships. One of these lordships involved Paracuellos de Jarama y Malagón, which became a marchisate in 1599.

Subsequently, from the 17th century onwards, the Lords of Paracuellos and Marquises of 
Malagón established family relations with other noble houses in Spain, as a result of which their archives passed into the hands of the Dukes of Santisteban del Puerto during the 18th century and, later, in 1818, into the hands of the Dukes of Medinaceli.

This paper aims to make known the archives of the Lords of Paracuellos, from their creation to the present day. We will provide detailed analysis of the documents contained and will also cast some light upon how they are currently organised and arranged, with a view to facilitating future studies of these documents. In terms of the methodology used, we have not only worked on the documentary collection kept in the Medinaceli Ducal Archives - the object of this study - reviewing their inventories and analyzing the reverse of each documentary item, but have also analysed the reference documentation preserved in other archives.

Key words: Marshals of Castile, Marquises of Malagón, family archives, signeurial documentation, Pardo-Tavera family

Toponyms: Paracuellos de Jarama

Period: 12th-19th centuries.

\section{INTRODUCCIÓN}

El señorío de Paracuellos de Jarama, entre Madrid y Alcalá de Henares, tras la conquista del territorio por Alfonso $\mathrm{VI}$ a fines del siglo XI pasó a formar parte del reino de Castilla bajo jurisdicción, primero, del arzobispo de Toledo. Un siglo después, con Alfonso VIII, tras un efímero período como señorío laico, se convirtió en encomienda de la orden de Santiago a fines del siglo XII y así permanecerá hasta mediados el siglo XVI, cuando las mesas maestrales pasaron a la jurisdicción real y Carlos I la vende en 1542 al mariscal de Castilla Arias Pardo de Saavedra, pasando a esta familia como señorío laico de orden regular. Poco después, en 1548, el propio señor de Paracuellos compra a la Corona la encomienda calatrava de Malagón, en tierras manchegas, un señorío que se convierte en 1599 en marquesado por merced del rey Felipe III.

Los señores de Paracuellos, marqueses de Malagón y mariscales de Castilla de la Casa Pardo-Tavera, por sucesivas alianzas matrimoniales, entroncaron a principios del siglo XVII con otras casas nobiliarias como la de los Ulloa, condes de Villalonso, y luego con la de Saavedra, condes de Castellar. E incluso, todas juntas, ya en el siglo XVIII se iban a agregar a la Casa de Santisteban del Puerto, con la que llegó el señorío de Paracuellos de Jarama a la Casa de Medinaceli, a punto ya de extinguirse los señoríos jurisdiccionales.

Como consecuencia de todas esas alianzas, el archivo patrimonial de los señores de Paracuellos de Jarama, mariscales de Castilla, integrado con escrituras que desde el siglo XI estaban en el convento de Uclés de la orden de Santiago y creado en el siglo XVI en la propia villa madrileña de la cuenca media del Jarama, dentro de la casa-palacio que allí tuvieron los Pardo-Tavera marqueses de Malagón, se transfirió a Madrid en el siglo XVIII para incorporarse, primero, al de Santisteban del Puerto en el palacio que estos tenían en la Plaza de San Pedro y, con él en 1818, al Archivo General de la Casa Ducal de Medinaceli en el majestuoso palacio que estos poseían en el Paseo del Prado. En tales unidades archivísticas superiores se acabó de organizar el fondo señorial de Paracuellos, como el del marquesado de Malagón, bajo los parámetros establecidos por estos nobles en sus archivos.

Nuestro objetivo aquí no es otro que difundir los contenidos de este archivo señorial paracuellense, además de perfilar su sistema de organización documental durante los siglos XVIII y XIX, así como trazar la evolución secular del fondo archivístico desde su etapa de encomienda de la orden de Santiago y, fundamentalmente, a partir de mediados del siglo 
XVI cuando pasó a la jurisdicción de los mariscales de Castilla y marqueses de Malagón. Todo ello, tras tratar primero la evolución histórica de estos Pardo-Tavera y su evolución hasta agregarse a los Medinaceli.

Para ello, metodológicamente, no sólo hemos trabajado en el fondo documental objeto aquí de estudio, revisando sus inventarios y analizando las marcas dorsales de cada pieza documental, sino también otra documentación de referencia conservada en la colección Salazar y Castro de la Real Academia de la Historia, el Archivo Histórico Nacional y el Archivo de la Nobleza española.

\section{CASA, LINAJE, OFICIO Y TERRITORIO: PARACUELLOS, DE ENCOMIENDA SANTIAGUISTA A SEÑORÍO DE LOS MARQUESES DE MALAGÓN}

El valle del Jarama fue siempre un punto de paso crucial de comunicación entre las dos Castillas. La reconquista del territorio se realiza por las huestes del rey Alfonso $\mathrm{VI}$ a fines del siglo XI, consolidándose a partir de la toma de Toledo en 1085. Entonces Paracuellos, asentado sobre un cerro en la cuenca media del río desde donde se domina la vega del Jarama, pasó a manos cristianas como parte del reino castellano-leonés, incorporándose al arzobispado de Toledo.

\subsection{Paracuellos, encomienda de la orden de Santiago}

Bajo jurisdicción de la mitra toledana con el arzobispo Bernardo de Sèdirac, este recibió como señorío el derecho a cobrar tributos y administrar justicia sobre la población, en compensación a su participación en la lucha contra los almorávides.

Más tarde, por privilegio rodado de 23 de julio de 1175 dado por Alfonso VIII desde "Trepeana" (Treviana), el rey dona la villa y el castillo de Paracollos a su fiel servidor, el caballero Ferrán Martínez de Hita (hijo de Fernando García de Hita y Estefanía Armengol), comendador de Uclés, para sí y sus sucesores, en remuneración a los servicios prestados ${ }^{1}$. Sin embargo, no se va a perpetuar el señorío paracuellense en poder de aquel linaje ${ }^{2}$ por cuanto veinte años después, el 28 de julio de 1195, el lugar fue donado por el propio monarca castellano a la orden de Santiago en la persona de su maestre, Sancho Fernández ${ }^{3}$.

Posteriormente en Palencia, el 18 de mayo de 1217 el maestre santiaguista García González de Arauzo y el convento de Uclés dan la posesión vitalicia de Paracuellos al procurador del rey-niño Enrique I, el conde Alvar Núnez de Lara, y a su mujer Urraca Díaz, junto con el propio castillo de Malsobaco, situado al suroeste del término ${ }^{4}$. Más tarde aún, en 1243, Gil Gómez do Vinhal renuncia al castillo de Híjar y otras tres fortalezas en la Sierra de Segura (Vicorto) y sus estribaciones orientales (Guta y Abejuela) que poseía, en favor de la orden de Santiago, a cambio de la encomienda de Paracuellos, que le fue entregada en prestimonio ${ }^{5}$.

1 Archivo Ducal de Medinaceli (en adelante ADM), Privilegios Rodados, $n^{\circ} 1$. Véase Sánchez, 2012: 397399. Fue editado antes por González, 1960: II, 384-386 (doc. 230) y por Romero Tallafigo et al., 2003: 112-113 (doc. 10). Ya era conocido por García del Arroyo, [1946]: 73 (doc. 76).

2 En 1178 y 1179, suscribe Ferrán Martínez de Hita con su primo Armengol de Urgel sendas escrituras de convenio y concordia, respectivamente, sobre la heredad de Paracuellos. Real Academia de la Historia (RAH) Colección Salazar y Castro (Col SyC), leg. B, carp. 10, nº 50 y fol. 40v.

3 ADM, Privilegios Rodados, $n^{\circ} 5$ (Procedencia: ADM, Paracuellos, 1-2). Véase Sánchez, 2012: 146-147 (doc. 646). En 1190, según el Tumbo antiguo de Castilla, libro II, carta 15, Ferrán Martínez de Hita y su esposa Urraca donan Paracuellos a la Orden (RAH, Col SyC, leg. B, carp. 10, fol. 41). Véanse los trabajos de Segura, 1982 y Urquiaga, 2000.

4 RAH, Col SyC, leg. M, carp. 8, fols. 22-23.

5 Archivo Histórico Nacional (AHN), Ordenes Militares, Uclés, leg. 328, núm.13 y carp. 260, nº 9. RAH, Col SyC, leg. M, carp. 8, fol. 43. Véase Rivera, 1985: 401 (doc. n 193). 
La encomienda estaba constituida por la villa de Paracuellos y los despoblados de Belvís, Viñuelas, El Burrillo y Cobeña, así como varios bienes en Vallecas y Móstoles (Porras, 1997: 236).

Parece ser que el rey Alfonso XI la vende más tarde al arzobispo de Toledo Gil de Albornoz, pero Paracuellos -con Belvís y Mohernando- hubieron de ser devueltos por el prelado a la Orden el 28 de junio de 1350 por mandato de Pedro I (López Agurleta, 1719: 315 y Jara, 1914: 156-159).

Años después era comendador de Paracuellos Ruy Garcés de Aza (1359-1366) y, más adelante, Fernán Díaz de Santacruz (1387-1409), pasando en el último tercio del siglo XV a ser gobernada la encomienda por los señores de Ayala, primero Pedro de Ayala, capitán de la gente de la provincia de Castilla en la campaña granadina de 1488 y, a continuación, su hijo Juan, regidor de Toledo. Los Ayala serían desbancados en 1509 por Alonso de Aragón, duque de Villahermosa, sobrino del rey Fernando el Católico, y años después fue comendador de Paracuellos Álvaro de Loaysa (Salazar y Castro, 1949: I, 270).

Más adelante, en el segundo cuarto del siglo XVI, siendo comendador el primer marqués de Montesclaros Rodrigo de Mendoza y Luna, se va a poner en marcha el procedimiento de enajenación de la encomienda y su conversión en señorío laico.

La razón estaba muy clara. Ávida, a la vez que falta, la hacienda pública de recursos para poder atender la política imperialista de Carlos $V$ y, con base legal en una serie de bulas pontificias como la de Adriano VI de 4 de mayo de 1523 que ponía en manos del monarca la administración de las mesas maestrales para que pudiese atender la lucha contra el infiel en las campañas que sostenía el emperador, el papa le otorga en 1529 amplia facultad para desmembrar y separar perpetuamente de las órdenes de Santiago, Calatrava y Alcántara algunos lugares, castillos, jurisdicciones y bienes, de los que podía disponer el rey como cosa propia hasta alcanzar la cantidad de 40.000 ducados de renta ${ }^{6}$. Esta secularización se inicia pujante en el reinado del propio rey Carlos I y prosigue en el de su hijo Felipe II.

Siguiendo el protocolo convenido, era necesario obtener previamente el consentimiento del comendador y, una vez tomada posesión de la encomienda por el delegado regio, podía aprobar el monarca la enajenación haciéndose inmediatamente la efectiva incorporación a la Corona. Así va a ocurrir en el caso de Paracuellos.

\subsection{El primer señor y su gran valedor}

En 1541, el comendador de Paracuellos marqués de Montesclaros otorga el preceptivo permiso para la enajenación de la encomienda santiaguista ${ }^{7}$. Y de inmediato el rey aprobó la venta.

El comprador no era otro que el mariscal de Castilla Arias Pardo de Saavedra (c.15091561), quien, gracias a la importante intervención mediadora ante el rey del más importante de sus asesores, se hizo con la desmembrada encomienda de Paracuellos de Jarama. La operación se produjo el 9 de junio de 1542, en que se suscribió la correspondiente escritura de compraventa entre el mariscal y el rey Carlos I por un coste de 42.024 .579 maravedís $^{8}$. El dominio adquirido por Arias Pardo incluía, además de Paracuellos, el coto de Belvís y las dehesas de Viñuelas, El Burguillo, Palomarejo y Cobeña, así como distintas propiedades en Vallecas y Móstoles. Y la fórmula de transmisión era el mayorazgo regular, por línea de primogenitura.

6 Sobre el desmembramiento de antiguas encomiendas militares, véase Moxó, 1961.

7 AHN, Consejos, leg. 32311, $\mathrm{n}^{\circ}$ 2, fols. 21 y ss.: Memorial ajustado del pleito entre el Fiscal del Consejo y el Duque de Medinaceli, como marido de la Duquesa de Santisteban y Marquesa de Malagón, sobre incorporaci6n a la Corona de la villa de Paracuellos, con su fortaleza, jurisdicción, alcabalas y demás derechos. Madrid, 1825. Es un doc. inserto, cit. por Moxó, 1961: 329.

8 ADM, Paracuellos, 2-2. 
[...] vendemos a vos Arias Pardo, mariscal de Castilla, para vos y vuestros herederos y sucesores después de vos, y para quien vos quisiéredes o por bien tuviéredes... título o causa para siempre jamás de la villa de Paracuellos, con su fortaleza y con todos sus términos y dependencias, montes, prados, pastos, dehesas, abrevaderos, aguas estantes, corrientes y manantes, y con todos sus vasallos, jurisdicción civil y criminal, mero y mixto imperio $[\ldots]^{9}$.

El mediador que actuó en la operación fue el único tío paterno de Arias Pardo de Saavedra, Juan Pardo Tavera, arzobispo de Toledo y cardenal primado de España, quien además cedía al mariscal para la adquisición de aquella extinta encomienda la cantidad de 19.703.829 maravedís, es decir, casi la mitad del montante de la compraventa ${ }^{10}$.

No fue esta la única donación que el cardenal hacía a "nuestro sobrino, que se a criado en nuestra cassa e tenemos en lugar de hijo", único hijo varón de su hermano mayor Diego de Deza, pues desde décadas atrás le venía haciendo importantes legados de casas, heredades y cortijos en el reino de Sevilla, de los que progresivamente se fue desprendiendo el prelado.

Así, la primera escritura de donación a favor de su sobrino ya la había otorgado Juan Pardo Tavera en Sevilla el 8 de octubre de 151711, siendo obispo de Ciudad Rodrigo y residente en la ciudad hispalense, aún en vida de su único hermano ${ }^{12}$, y afectó a diversos bienes rústicos en Constantina (heredad de Majalimar, donadío de las Santeras...) y parte de los que poseía en el lugar de Villanueva del Río (donadíos de la Vega y Antona Pérez, etc. $)^{13}$. La segunda escritura había sido suscrita en Valladolid el 16 de marzo de 1524, siendo Tavera obispo de Osma, y se trató de un conjunto de bienes que poseía en término de Utrera (donadíos de Pardales, Zarracatinejos y otros), más los que tenía en Valencina del Hoyo o del Alcor (tierras de La Lampa) y parte de los de Villanueva del Río ${ }^{14}$. Y aún hubo una tercera escritura de donación, dada en Medina del Campo el 1 de julio de 1532 siendo ya Juan Tavera arzobispo de Santiago de Compostela, donándole los bienes que tenía en Las Cabezas de San Juan (donadío de La Palmilla) y algunas rentas en la ciudad de Sevilla ${ }^{15}$.

Pero, además, Arias Pardo había recibido en su momento la correspondiente herencia de sus progenitores. Así, en 1517, a la muerte de su padre Diego Pardo de Deza, heredó los bienes que le correspondieron. Este, en su testamento, mejoró a su único hijo varón legítimo en el tercio de todos sus bienes:

[...] quiero y es mi voluntad que pueda aver y aya el dicho tercio y remanente del quinto de todos mis bienes en toda mi heredad, que yo he e tengo en Valencina del Alcor, lugar del Axarafe de Sevilla, en que hay casas y molinos de moler aceituna e olivares y casas de cogederas, y con todo a la dicha heredad anexo y perteneciente $[\ldots]^{16}$.

9 Ibídem. Moxó reproduce el dispositivo en las pp. 343-345 del mismo trabajo.

10 Véase ADM, Malagón, 6-12, documento extractado por Campo, 1997: 740-746.

11 ADM, Partido de Sevilla, 1-1.

12 Podría ya encontrarse enfermo Diego de Deza, padre de Arias Pardo, pues había testado en Sevilla el pasado 5 de septiembre (ADM, Partido de Sevilla, 2-58) y falleció poco después dentro del mismo año de 1517.

13 Un desglose de los bienes del obispo Tavera en el reino de Sevilla, con el pormenor de los muchos de ellos donados sucesivamente a Arias Pardo, en Sánchez (en prensa).

14 ADM, Partido de Sevilla, 1-2.

15 ADM, Partido de Sevilla, 3-52. En la referencia a esta donación, es donde el cardenal llama a Arias Pardo «nuestro sobrino, que se a criado en nuestra cassa e tenemos en lugar de hijo» (ADM, Partido de Sevilla, 1-4).

16 ADM, Partido de Sevilla, 2-58. 
También recibió Arias Pardo en 1526 diversos bienes a la muerte de su madre María de Saavedra, la mayor de las hijas del mariscal de Castilla Gonzalo de Saavedra, que vivía por entonces ${ }^{17}$. Salazar y Mendoza (1603: 389), se refería a esta herencia, en palabras más bien hiperbólicas, refiriendo que "succedió en una casa muy rica". También su tía materna Juana de Saavedra hizo una cesión de su legítima herencia paterna y materna en su sobrino Arias Pardo con fecha 20 de agosto de $1532^{18}$. Un año antes falleció su abuelo materno, Gonzalo de Saavedra, de quien recibió la mariscalía de Castilla y el cargo de alcalde mayor de la ciudad de Sevilla además de otros bienes.

Sin embargo, no cabe la menor duda de que la mayor parte del patrimonio de Arias Pardo le llegó al mariscal de su tío el cardenal Tavera.

\subsection{Señores de Paracuellos y marqueses de Malagón}

Fue tanta la hacienda recibida por Arias Pardo que solo tres años después de la desaparición de su gran benefactor, el cardenal Tavera, que falleció en Valladolid el $1^{\circ}$ de agosto de 1545, con parte de la herencia de su propio tío, el mariscal pudo también comprar al rey Carlos I, el 14 de enero de 1548, otra antigua encomienda militar, en este caso la calatrava de Malagón, por una cifra cercana a los 56 cuentos de maravedís ${ }^{19}$, siendo así la más valiosa de la treintena de encomiendas que segregó el monarca para poder atender los elevados gastos del Imperio hispánico Cepeda, 1980: 505). Próxima a Ciudad Real, esta extinta encomienda poseía unos bienes tasados en una cantidad próxima a los cien millones de maravedís (Franco, 2001: 270-271). Al comprender las villas de Porzuna y Fuente el Fresno, Malagón poseía un vasto patrimonio, con una economía esencialmente ganadera y una serie de tributos y rentas que hacían el señorío apetecible a cualquier noble de la época (Franco, 2001: 274).

Según Salazar y Mendoza (1603: 389), como parte de pago de lo que le costó el señorío de Malagón, entregó el mariscal Arias Pardo la alcaldía mayor de la justicia de Sevilla (por valor de más de 24.000 ducados) y la veinticuatría de la ciudad (valorada en 7.000 ducados), más 100.000 maravedís de juro, y 12.000 ducados de la venta de sus casas que tenía en la collación de San Juan de la Palma de la ciudad de Sevilla. Por su parte, los documentos conservados en el Archivo Ducal de Medinaceli y otras fuentes consultadas, precisan los bienes de los que hubo de desprenderse Arias Pardo, de su patrimonio en el reino de Sevilla. Principalmente, aclara la cuestión el documento fechado el 28 de octubre de 1548 en la villa de Castelló de Empùries, por el que el rey Carlos I le concede a su mariscal de Castilla facultad para vender diversos bienes ${ }^{20}$, entre los que se incluían las casas que poseía en la calle de Abades de Sevilla -confirmada su venta en 155921-, la heredad de Majalimar, las haciendas de Villanueva del Camino y Valencina del Hoyo ${ }^{22}$ y las aceñas llamadas de las Casas, sitas junto al Guadalquivir en término de Villanueva, para contribuir con su importe a pagar a S.M. el precio en que le vendió la villa y encomienda de Malagón. Además,

17 Por un inventario de bienes mandado a realizar por el propio Arias Pardo a fines de 1548 de toda su hacienda en la ciudad de Sevilla y su tierra, al que luego aludiremos, conocemos todo su patrimonio por entonces (ADM, Partido de Sevilla, 5-28).

18 ADM, Partido de Sevilla, 10-49.

19 ADM, Malagón, 1-21, AHN, Órdenes (Consejo), leg. 4401 y Archivo Histórico de la Nobleza (AHNOB), Frías, caja 1487 n 1. Véase Campo, 2000.

20 ADM, Partido de Sevilla, 1-13 y 5-17.

21 ADM, Partido de Sevilla, 5-17 (Sevilla, 16 agosto 1559). En la autorización solicitada al rey para la venta de dichas casas, que se tasa en 40.000 ducados, se incluye también la heredad de Valencina del Alcor.

22 Esta vendida por entonces a Diego Caballero, mercader y funcionario de la Casa de Contratación. Véase Otte, 2003: 331. 
pierde Arias Pardo el oficio de la alcaldía de Sevilla, que había heredado de su abuelo materno Gonzalo de Saavedra, siendo compensado por Carlos I con 10.000 ducados (Franco, 2001: $270)^{23}$. Con el mismo fin de saldar su deuda sobre Malagón, al año siguiente, el 27 de octubre de 1549, Arias Pardo vende a Alonso Pesguer un juro de 40.000 maravedís anuales sobre el almojarifazgo mayor de Sevilla y otras rentas de la ciudad ${ }^{24}$. También por entonces estipula el mariscal la venta a Diego González de Medina de un juro de 50.000 maravedís sobre las alcabalas de las carnicerías de Sevilla ${ }^{25}$, rentas que Arias Pardo ya había comprometido para entregarlas a la Corona como parte del pago aplazado (Campo, 1997: 115).

Arias Pardo tomó así posesión, como señorío pleno, de una antigua encomienda situada en pleno Campo de Calatrava que no había resultado nada barata, sino todo lo contrario. Aspiraría a ser señor de vasallos y lo había conseguido. Fue lo que siempre había perseguido la línea de los primeros mariscales de la Casa de Saavedra.

Tabla 1. Genealogía de la Casa de Pardo-Tavera, marqueses de Malagón y señores de Paracuellos

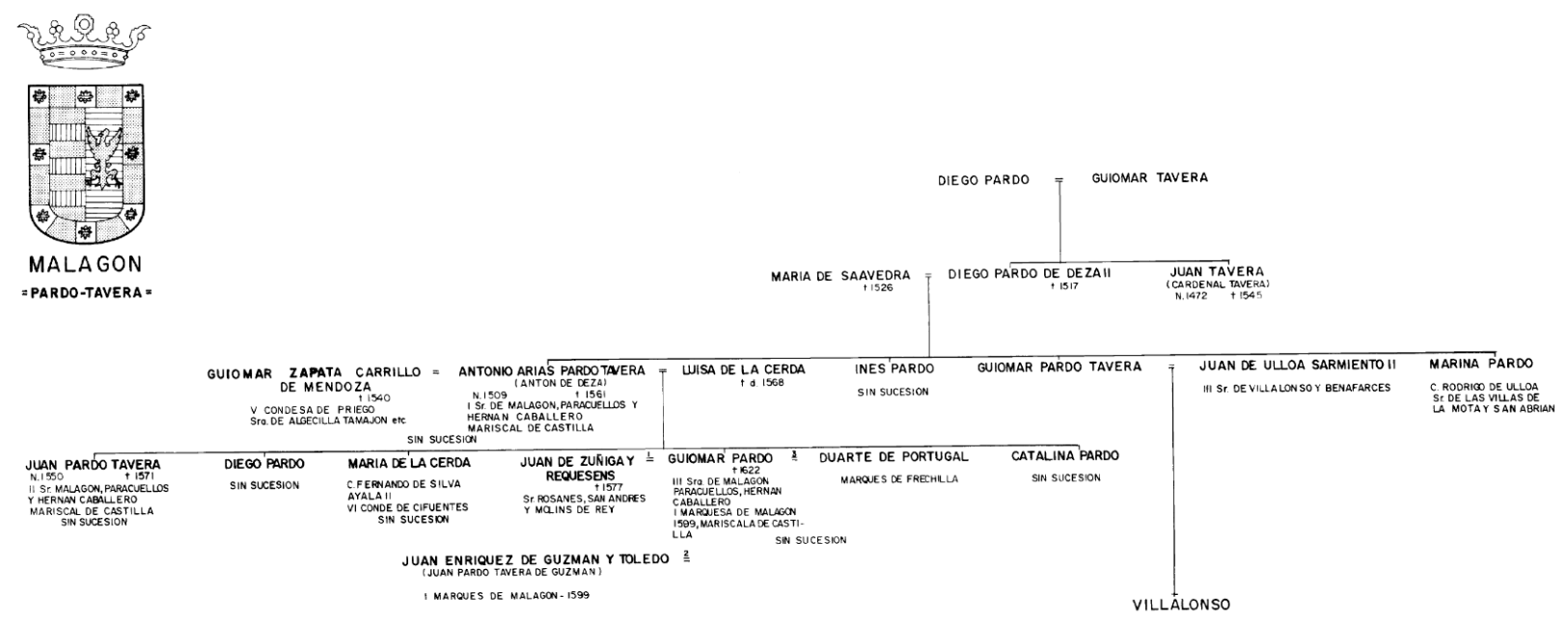

Fuente: Elaboración propia

Evidentemente para entonces, a mediados del siglo XVI, el estado de Malagón y sus señoríos agregados tenían más que perfilados sus límites territoriales. El dominio principal quedaba emplazado en la zona septentrional de la actual provincia de Ciudad Real lindando con la de Toledo. Los montes toledanos le daban así la linde norte; por el este, confinaba el estado con los términos de Villarrubia de los Ojos, Daimiel y Torralba de Calatrava; por el sur, esta misma población y la de Piedrabuena, junto con el señorío agregado de Fernán Caballero; y por el oeste, servían de límites los términos de Retuerta del Bullaque y Alcoba de los Montes. Por la parte más occidental, el estado de Malagón incluía el lugar de Porzuna, que atravesaba el río Bullaque y la cañada real toledana; le seguía la capital, Malagón, cuyo término quedaba cruzado por las aguas del Bañuelos; más al norte quedaba el lugar de

23 Dicha cantidad la abonó la propia ciudad de Sevilla.

24 ADM, Partido de Sevilla, 9-46. En concreto, aparte de esos 40.000 maravedís, otros juros de heredad de 30.000 maravedís de las mercadurías, de 5.000 de la renta del pescado fresco y de 5.000 del diezmo del aceite de las puertas.

25 ADM, Partido de Sevilla, 5-33 (copia simple, s.f. [1549]). Aunque el documento no está datado, la fecha se deduce al indicarse en su texto que el cobro del juro tendría efecto a partir de $1^{\circ}$ de enero del siguiente año de 1550. 
Los Cortijos; y, por el este, Fuente el Fresno, como dominio más oriental ${ }^{26}$. En conjunto, la extensión superficial del marquesado se aproximaba a los 891'95 kilómetros cuadrados.

Fuera quedaban los dos señoríos agregados: el de Fernán Caballero, que lindaba con la parte meridional del estado principal (103'55 kilómetros cuadrados) y, obviamente, el que aquí venimos tratando de Paracuellos (con 43'87 kilómetros cuadrados).

Era ya momento de garantizar la sucesión de los nuevos bienes adquiridos en el mayorazgo familiar (Paracuellos y Malagón, especialmente), lo que hizo el mariscal el 26 de julio de $1557^{27}$, imponiendo el apellido Pardo-Tavera y armas correspondientes al heredero (en recuerdo de su tío, el cardenal), un mayorazgo que confirmará después en su último testamento.

Previamente, en Toledo, el 11 de junio de 1560 le otorga el rey Felipe II -a petición del propio Arias Pardo- real provisión facultando a su mariscal de Castilla para subrogar los bienes que poseía en el reino de Sevilla por donación y vínculo de su tío D. Juan Pardo Tavera, desde cuando este era obispo de Ciudad Rodrigo y de Osma, a la vez que para ampliar el mayorazgo incluyendo las villas de Malagón y Porzuna ${ }^{28}$.

No sólo estas, sino también Paracuellos de Jarama con sus posesiones anejas, fueron incluidas finalmente en el citado mayorazgo que ratificó Arias Pardo el 9 de enero de 1561, al tiempo de ordenar su testamento ${ }^{29}$. Cinco días después fallecía en Toledo.

El beneficiario de esta rica herencia, por la línea de primogenitura que imponía este mayorazgo regular, sería el primogénito - llamado como el cardenal, Juan Pardo Tavera- de los cinco hijos habidos del segundo matrimonio del mariscal con Luisa de la Cerda, hija del segundo duque de Medinaceli Juan de la Cerda. Sin embargo, Juan Pardo Tavera (15501571), II Señor de Paracuellos, Malagón y Fernán Caballero, no pudo disfrutar mucho tiempo de este mayorazgo pues apenas vivió 21 años, siendo su madre quien se ocupara de administrar los bienes (Sánchez, 2016: 211).

Muerto el joven Juan Pardo, soltero y sin descendencia, el 22 de octubre de 1571, otra hija de Arias Pardo y de Luisa de la Cerda, llamada Guiomar Pardo Tavera (†1622), sucede en el mayorazgo también en edad juvenil. Tres años después de esta herencia, la señora de Malagón y Paracuellos contraía nupcias con Juan de Zúñiga Requesens, señor de Martorell, un matrimonio que se truncaba al poco tiempo por muerte de éste; y en 1578 casaba de nuevo la joven Guiomar con Juan Enríquez de Guzmán y Toledo, hijo de los condes de Alba de Liste. A estos, el 16 de febrero de 1599, el recién entronizado monarca Felipe III les concedió conjuntamente -a él con nombre de Juan Pardo, precisamente por imperativo del mayorazgo- el título de primeros Marqueses de Malagón ${ }^{30}$, elevándose de esta forma a rango de marquesado el antiguo dominio calatravo.

26 Una profundización de la evolución histórica de estos lugares y de sus aspectos geográficos en Corchado, 1982 y 1984.

27 ADM, Malagón, 6-9. Véase también ADM, Paracuellos, 7-60.

28 ADM, Partido de Sevilla, 1- 2.

29 ADM, Malagón, 6-11.

30 ADM, Archivo Histórico, 272-34 (antigua caja 2 n 34-R). 
Figura 1. Título de marqués de Malagón. Real provisión de Felipe III (1599)

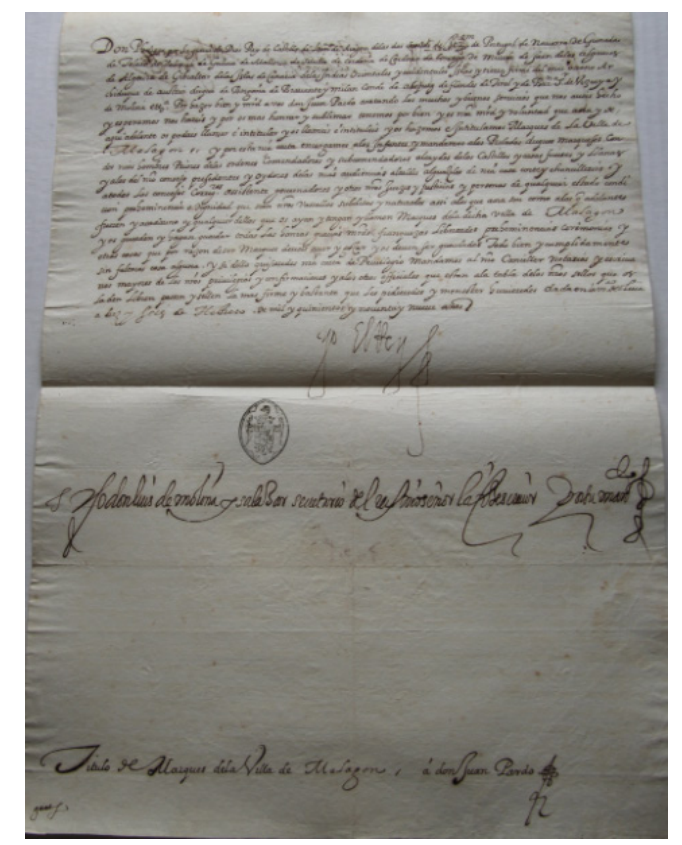

Fuente: ADM, Archivo Histórico, leg. 272, nº 34

Sin embargo, ninguno de ambos matrimonios, ni un tercero contraído en 1606 por $\mathrm{D}^{\mathrm{a}}$. Guiomar con el marqués de Frechilla Duarte de Portugal ${ }^{31}$, le dieron a la marquesa de Malagón descendencia alguna, extinguiéndose con ella en 1622 la línea de los Arias Pardo-Tavera.

Esta anómala circunstancia, tras la resolución de una serie de pleitos en cuyo tiempo el marquesado de Malagón quedó vacante, fue la que hizo recaer este estado y sus señoríos anexos de Fernán Caballero y Paracuellos de Jarama en Diego de Ulloa Sarmiento (†1647), II conde de Villalonso, por su mejor derecho a la sucesión al descender de una tía de la última titular de esos estados, también llamada Guiomar Pardo, hermana de Arias Pardo y esposa de su bisabuelo, el tercer señor de Villalonso y Benafarces Juan de Ulloa Sarmiento ${ }^{32}$.

Sin embargo, no tuvo ninguna posteridad el heredero Diego de Ulloa del matrimonio que contrajo con Antonia de Benavides, una hija de los VII condes de Santisteban del Puerto, ni de otro anterior con su prima Magdalena Sarmiento y Ulloa. Por esa razón, a su muerte en 1647, su hermana Francisca de Ulloa Sarmiento se convertía desde entonces en III marquesa de Malagón, III condesa de Villalonso y señora de Paracuellos, Benafarces y Fernán Caballero, entre otros dominios.

Para entonces esta señora había contraído nupcias, desde 1609, con su primo hermano Gaspar Juan Arias de Saavedra, V conde del Castellar y señor del Viso, y había enviudado de él ${ }^{33}$. En consecuencia, todos estos estados patrimoniales de los extintos Pardo-Tavera y los Ulloa pasarían al primogénito de estos, Fernando Miguel Arias de Saavedra y Ulloa, agregados a la Casa de Castellar, titulándose así VI conde de Castellar, III marqués de Malagón y IV conde de Villalonso, además de mariscal y alfaqueque mayor de Castilla. Este enlace venía a suponer la unión de las dos grandes ramas de Saavedra (la de los

31 Véase ADM, Malagón, 10-28: Capítulos matrimoniales para el enlace. Madrid, 17 abril 1606.

32 Véase ADM, Medinaceli-Desvinculación, 287-19. 
alfaqueques de Castellar y ésta de los mariscales de Malagón) surgidas a principios del siglo XV.

Fernando Miguel había casado en 1632 con Catalina de Acevedo ${ }^{34}$ y, en ausencia de varón del matrimonio -pues él fue el último en línea de primogenitura-, le sucedía su hija Teresa María Arias de Saavedra, esposa a su vez desde 1664 de Baltasar de la Cueva y Enríquez de Cabrera ${ }^{35}$, un hijo de los duques de Alburquerque que fue fiscal del Real Consejo de las Órdenes, consejero del Real y Supremo Consejo de Indias y gentilhombre de Cámara, además de virrey del Perú entre 1674 y 1678 (Fernández de Bethencourt, 1920: 309-313).

Sucedió a estos el primogénito del matrimonio Fernando Joaquín de la Cueva Arias de Saavedra (†1721) quien, aunque casado con María Antonia Ruiz de Castro Centurión, ante su temprana muerte sin descendencia en 1721, el mayorazgo pasó a su única hermana Ana Catalina de la Cueva Arias de Saavedra (1684-1735), titulada desde entonces VI marquesa de Malagón, IX condesa del Castellar y VII de Villalonso, otros títulos aparte. Esta señora era esposa, desde 1707, del X conde de Santisteban del Puerto -y luego I duque de aquel estado-, Manuel de Benavides y Aragón, por lo que aquellos títulos y dominios se incorporaron a la Casa de los Caudillos Mayores del reino de Jaén, que eran estos Benavides ${ }^{36}$.

En consecuencia, por esta alianza en adelante quedaba agregado el marquesado de Malagón, con la mariscalía de Castilla, cuyos titulares seguían poseyendo una administración en Sevilla con los bienes de aquel antiguo reino, a la Casa de Santisteban del Puerto, arrastrando consigo el condado de Castellar de los Arias de Saavedra y el condado de Villalonso de los Ulloa. Y todos juntos, en dicha Casa de Santisteban, se incorporarían a la ducal de Medinaceli a fines del mismo siglo XVIII al contraer matrimonio en 1764 los entonces herederos de las respectivas casas nobiliarias. Por un lado, Joaquina María de Benavides y Pacheco (1746-1805), marquesa de Solera y luego III duquesa de Santisteban del Puerto -nieta del citado D. Manuel-y, por otro, Luis María Fernández de Córdoba y Gonzaga (1749-1806), marqués de Cogolludo y futuro XIII duque de Medinaceli (Sánchez, 2015: 6062). El heredero de este vasto patrimonio sería el hijo de ambos, Luis Joaquín Fernández de Córdoba y Benavides (1780-1840), XIV duque de Medinaceli y IV de Santisteban del Puerto, IX marqués de Malagón y tantos otros títulos, a quien cogió la abolición de los mayorazgos y del régimen señorial con la implantación del Régimen Liberal en España durante el primer cuarto del siglo XIX, consumada en $1841^{37}$, por lo que los dominios aquí tratados quedaban convertidos para los herederos en bienes de libre disposición.

\section{LOS ARCHIVOS DE LOS SEÑORES DE PARACUELLOS Y MARQUESES DE MALAGÓN}

El archivo del señorío de Paracuellos de Jarama mantenía su documentación en este lugar, pues los señores y marqueses de Malagón tenían allí una casa-palacio desde la adquisición del señorío por Arias Pardo a mediados del siglo $\mathrm{XVI}{ }^{38}$, inmueble que servía además como sede de la administración señorial.

Por su parte, el archivo del estado principal de la Casa se hallaba emplazado en Malagón, junto con los documentos del señorío colindante de Fernán Caballero, dentro del

34 ADM, Castellar, 5-16: Capítulos matrimoniales para este enlace (6 de noviembre 1632).

35 ADM, Castellar, 5-25.

36 Un estudio muy completo de esta casa nobiliaria en Sánchez, 2015.

37 Véase Sánchez, 2017: 331.

38 Este palacio hoy alberga la Casa de Niños Picón, centro educativo perteneciente a la Comunidad de Madrid, que conserva el patio del siglo XVI. 
histórico castillo de la villa que había sido adaptado a casa-palacio por Arias Pardo y Luisa de la Cerda en el tercer cuarto del siglo XVI tras la adquisición de la extinta encomienda (Melero, 2005: 60-61). Sabemos incluso que el nuevo titular del señorío hubo de reclamar al Sacro Convento de Calatrava la entrega de los documentos originales del anterior período calatravo ${ }^{39}$ y lo mismo debió hacer al Convento de Uclés para con la documentación de Paracuellos.

Además, los marqueses de Malagón y señores de Paracuellos poseían en Sevilla el archivo patrimonial originario de los antiguos mariscales de Castilla de la Casa de Saavedra que los Pardo-Tavera conservaron para administrar las posesiones de la zona, que también se nutría del fondo documental legado a la familia en las primeras décadas del siglo XVI, el por entonces canónigo, chantre y provisor del cabildo catedralicio hispalense, además de vicario general de aquel arzobispado, D. Juan Pardo Tavera, que formó parte del originario archivo personal del futuro cardenal primado.

En estas tres sedes (Paracuellos, Malagón y Sevilla) permanecieron los fondos de estos nobles hasta bien entrado el siglo XVIII. Eran, por tanto, tiempos en los que los archivos señoriales se mantenían cercanos a los estados administrados.

\section{INTEGRACIÓN DEL FONDOS DOCUMENTAL EN UNIDADES ARCHIVÍSTICAS SUPERIORES: ORGANIZACIÓN Y DESCRIPCIÓN}

Más adelante, cuando el señorío de Paracuellos y el marquesado de Malagón, con el condado de Villalonso ${ }^{40}$, se incorpora a mediados del mismo siglo XVII a la Casa de Castellar ${ }^{41} y$, más tarde aún, cuando todos esos títulos, estados y propiedades se agregaron en las primeras décadas del siglo XVIII a la Casa de Santisteban del Puerto, no parece que sus titulares tuvieran previsto aún ningún tipo de medidas tendentes a la concentración de los dispersos depósitos documentales, al menos en un primer momento. Sin embargo, la política de concentración archivística de los Benavides no se haría esperar, tal vez emulando el imperante centralismo borbónico.

\subsection{Agregación a unidades archivísticas superiores}

Efectivamente, escasos años después todos esos fondos documentales dispersos, junto con otros que también poseían estos Benavides en los diversos estados patrimoniales, fueran reclamados por sus titulares para incorporarse al Archivo General de la Casa de Santisteban del Puerto en Madrid.

Estos condes -duques a partir de 1739- tenían por entonces su morada principal en Madrid, en la casa-palacio o "Casa Grande" que poseía la familia frente a la iglesia de San Pedro el Viejo, esquina la calle Pretil de Santisteban con la calle del Nuncio ${ }^{42}$. Y, por entonces, los Santisteban ordenan la transferencia hasta aquel edificio madrileño de todos y cada uno de esos numerosos archivos que la Casa tenía repartidos por sus cuantiosos estados, un proceso que se produjo entre 1720 y 1751, principalmente por los años treinta ${ }^{43}$.

39 ADM, Malagón, 2-2. En el documento se expresa que "[...] se le han de entregar originalmente todas las escrituras, bulas, provisiones, privilegios, visitaciones, amojonamientos y otras qualesquier escrituras que estuvieren en el dicho Archivo tocante a la dicha villa, sus terminos e jurisdiccion [...] para en guarda y conservacion de su derecho[...]". De ahí que la documentación del Archivo que nos ocupa arranque del año 1180, prueba evidente de que las escrituras fueron entregadas a los nuevos señores.

40 El archivo de este condado castellanoleonés radicaba entonces en la ciudad de Toro.

41 La documentación del condado de Castellar, también de los Saavedra, se emplazaba desde el siglo XV en el castillo-fortaleza de esta villa gaditana próxima a Gibraltar.

42 Sobre esta casa-palacio, consúltese ADM, Santisteban, 28-12 a 30. Véase Sánchez, 2015: $109-112$.

43 Véase todo el proceso de concentración archivística de los diversos fondos en Sánchez, 2015: 103-108. 
El primer conjunto documental que tomó rumbo hasta la capital del reino fue el del estado principal de Santisteban del Puerto y los de sus señoríos próximos y agregados de Solera, Espelúy e Ibros, desde tierras jienenses, lo que resulta del todo lógico. Estos fondos formarían, por tanto, el embrión o núcleo forjador del Archivo General de la Casa (Sánchez, 2015: 104). Los restantes integrantes se irían agrupando paulatinamente al depósito archivístico e incluso algunos de ellos se resistirían a llegar por el momento.

A continuación, los siguientes fondos que llegan a Madrid fueron precisamente los de los estados de Ana Catalina de la Cueva Arias de Saavedra, la esposa del conde Manuel de Benavides, entre ellos los de Paracuellos, el marquesado de Malagón y la contaduría sevillana de los bienes de los mariscales, que ya se encuentran en la capital del reino, junto al de Santisteban, al iniciarse la tercera década del mismo siglo XVIII ${ }^{44}$.

Más adelante, a raíz de la unión de las Casas de Santisteban del Puerto y Medinaceli, se propiciaría la ulterior integración de ambos archivos generales en un depósito único. Habría que esperar, no obstante, a que pasara la convulsa etapa de la Guerra de la Independencia española para que el heredero de ambas casas, Luis Joaquín Fernández de Córdoba y Benavides, ordenara en 1818 la transferencia del archivo de Santisteban a la sede del Archivo Ducal de Medinaceli, ubicado en el majestuoso palacio que estos tenían en el madrileño Paseo del Prado.

Y, en adelante, la documentación que aquí tratamos ya no abandonaría el Archivo Ducal de Medinaceli, tanto en Madrid (1818-1961) como después en la "Casa de Pilatos" de Sevilla (1961-1995) y, por último, en Toledo -desde 1995-, dentro del Palacio Tavera (antiguo Hospital de San Juan Bautista), donde hoy permanece.

\subsection{Organización y descripción documental}

Como ya dimos a conocer (Sánchez, 2015: 113-139), el principal artífice inicial de las tareas orgánicas y descriptivas sobre los fondos archivísticos de la Casa de Santisteban del Puerto, al que quedaron inicialmente integrados los del señorío de Paracuellos y marquesado de Malagón, fue el archivero Manuel Antonio Brochero (1735-1773). Su labor inicial se plasma en un informe autógrafo que elaboró a requerimiento del marqués de Solera, heredero de la Casa, para remitirlo a Italia al conde Manuel de Benavides, su padre. Dicho informe debió realizarlo entre 1735 y $1737^{45}$ y describe el estado de disposición documental de los fondos del depósito de los Santisteban por aquellas fechas señalando, al respecto, que

El estado de Malagón se compone de siete papeleras ó cajones [...], dos ocupa el partido de Paracuellos como caueza de esta Casa; otros dos ocupa el partido de Malagón; otros dos ocupa el partido de dicha ciudad de Seuilla por hauer en ella vienes [sic] pertenecientes a Castellar y Malagón; y el otro ocupa el partido de Toledo ${ }^{46}$.

Esta mención al fondo de Paracuellos viene a confirmarnos que este archivo señorial, como el marquesal de Malagón, ya habían llegado -juntos o por separado con esos otros fondos de sus dominios- a la Casa Grande madrileña de los Santisteban en esos años. Había, pues, una sección Paracuellos, otra Malagón y otra Sevilla (entre las 17 que componían por entonces el Archivo Ducal de Santisteban, una para cada uno de los estados

44 Véase ADM, Santisteban, 39-2, exp. 2.

45 ADM, Santisteban, 39-2, exp. 2. Transcrito el informe en Sánchez, 2015: 267-268.

46 ADM, Santisteban, 39-2, exp. 2, fol. 2. En definitiva, en esas unidades de instalación se encontraba la documentación del marquesado de Malagón, el señorío de Paracuellos de Jarama, los bienes de la administración de Sevilla y los bienes que tenían los Pardo-Tavera en Toledo. 
y administraciones señoriales ${ }^{47}$ ), cuya documentación ocupaba dos cajones o «papeleras» del depósito.

En estricta aplicación del principio de respeto a la procedencia de los fondos, quedó conformado el organigrama del Archivo General de la Casa de Santisteban, procediendo Brochero a la clasificación archivística de la mayoría de las secciones (entre las que se incluyen las de Paracuellos que venimos tratando y de Malagón) extractando pieza a pieza, cada una en su envoltura ${ }^{48}$.

A continuación, el archivero formó series con la documentación de cada fondo, unas series por lo general demasiado ambiguas, genéricas y concisas o poco aclaratorias (títulos de dominio, títulos de posesión, pertenencias de..., varios, "papeles inútiles", etc.), junto a otras más precisas (juros, censos, penas de cámara, casas, tierras y dehesas, etc.).

Luego se procedió a la ordenación de los documentos siguiendo un criterio cronológico, que se combinó con otro numérico, pues cada escritura así ordenada recibió un número correlativo dentro de su serie. Y se formaron legajos con los documentos ordenados, que también se numeraron correlativamente.

Fruto de este trabajo orgánico desarrollado por Brochero en el depósito documental de los Benavides en Madrid fue la elaboración de 15 tomos inventarios. Concretamente el que aquí nos interesa ${ }^{49}$ Ileva por título Libro del Estado de Paracuellos que, aunque sin fecha, fue elaborado y escrito por el archivero en torno a 1735. Forma un tomo con formato de marca mayor encuadernado en tafilete marrón "con sus fundas de vadana (sic)" y con grecas y decoración vegetal grabada en oro fino, al clásico estilo barroco español, con broche-cierre metálico. El inventario, compuesto de 713 páginas manuscritas, se iniciaba con un escudo de armas de los Arias Pardo pintado sobre pergamino que le fue arrancado posteriormente para la encuadernación de un nuevo inventario al que nos referiremos. Lo mismo le ocurrió al índice inicial de materias. A partir de la página 418 ese índice inicial se duplica, a modo de segunda parte del inventario con el fin de regestar futuras incorporaciones documentales, que no llegó a utilizarse nunca pues escasas décadas después se hace un nuevo inventario de la sección. Entre ambas partes del inventario, el manuscrito cuenta con unos asientos generales sobre los bienes, patronatos, regalías y censos de la Casa en este señorío madrileño de Paracuellos del Jarama.

Todo hace indicar que a mediados del siglo XVIII ya había culminado Brochero la labor orgánica de los fondos de la mayoría de los estados de la Casa de Santisteban del Puerto, incluidos los de Paracuellos y Malagón. La valoración final a todo su trabajo orgánico en el Archivo General de los Santisteban podemos calificarla sólo de aceptable, fundamentalmente por haber creado series muy imprecisas ${ }^{50}$ y por hacer regestas tan extensas, por lo general, que hacían perder el hilo del extracto. Por otro lado, el sistema de orden impuesto en la documentación no sirvió para mantener el rigor cronológico deseado en la disposición de los fondos. En su disculpa cabe indicar que hubo de realizar una inmensa tarea con escasa ayuda.

47 Pronto reducidas a 15 por agrupación de dos parejas de secciones homogéneas. Una de ellas fue, precisamente, la integración en la sección Malagón, de los papeles de la administración en Toledo de los Pardo-Tavera.

48 ADM, Santisteban, 39-2, exp. 2. Unas generalidades sobre los contenidos de los archivos nobiliarios en Lafuente, 2010: 38-73.

49 También hizo, obviamente, otro para la sección del marquesado de Malagón.

50 Esto repercutió en que, aún en nuestros días, resulte complejo a veces localizar un determinado documento dentro del fondo. 
La etapa de Brochero como archivero concluyó en $1773^{51}$ relevándole en el cargo un inoperante José Manuel de la Vega (1773-1782), cuya etapa fue transitoria en el depósito desde el punto de vista orgánico ${ }^{52}$. Le siguió su oficial Manuel de Terán (1783-1802) ${ }^{53}$, quien iba a ser el artífice de la conclusión y complementariedad de la organización documental de los fondos del archivo, actuando también sobre la sección Paracuellos ${ }^{54}$.

La restructuración hecha por Terán en esta sección, con respecto a la organización que ya tenían estos fondos desde tiempos de Brochero, consistió más que nada en subsanar algunas series ambiguas establecidas en la clasificación anterior, en delimitar mucho mejor las series territoriales y en fijar de forma más precisa series que antes habían quedado ocultas.

El resultado de la tarea organizativa de Manuel de Terán se plasmó en un nuevo inventario titulado igualmente Libro del Partido de Paracuellos [s.f. (1780-1795)], encuadernado en piel granate -con similar decoración floral grabada en oro al ya descritoy sin broches de cierre. El tomo tiene 436 folios, con grandes blancos intercalados entre cada serie, en previsión de futuras incorporaciones documentales. El escudo de armas que le antecede, obviamente de los Arias Pardo, es aquel pintado sobre pergamino que le había sido sustraído al inventario compuesto años atrás por Brochero para el mismo fondo, al que este de Terán reemplazó en su uso archivístico. Tiene, además, un índice de las materias en las que se estructura el manuscrito.

Entrado el siglo XIX, con la agregación de la Casa de Santisteban a la de Medinaceli personalizada en el duque heredero Luis Joaquín Fernández de Córdoba y Benavides, además IX marqués de Malagón y señor de Paracuellos, se va a producir un intento de homogeneización de los fondos de un archivo y otro (Santisteban y Medinaceli), ambos en Madrid, sobre todo después de la convulsa etapa de la guerra de la Independencia, cuando se produjo la transferencia del primero en 1818 al palacio de los Medinaceli en el Paseo del Prado $^{55}$. Por orden ducal de 4 de abril de ese año, el Archivo de Santisteban se incorporaba así al de Medinaceli, bajo la dirección única del archivero Juan Gil de Arana, ocupando una dependencia aparte, aledaña al antiguo depósito, en el propio palacio del Prado ${ }^{56}$.

Ya a fines del mismo siglo XIX, se va a consumar la organización total de los fondos y su descripción general. Así, cuando se realizó un recuento global de la documentación de los depósitos archivísticos de los duques de Medinaceli (Sánchez, 2014: 97) por parte del archivero-bibliotecario de José María Octavio de Toledo en $1886^{57}$, el fondo concreto del señorío de Paracuellos, junto con el de Malagón, se componían de 81 legajos, más 13 tomos sueltos, y se hallaba custodiado en doce papeleras (enumeradas correlativamente, con dos de ellas vacías), tal como aquí recogemos (tabla 2).

51 Ese mismo año el Archivo Ducal de Santisteban quedó reglamentado por las Instrucciones dadas desde Aranjuez por Antonio de Benavides, VII marqués de Malagón, señor de Paracuellos, II duque de Santisteban y otros tantos títulos.

52 Este archivero, en realidad, aportó muy poco (Sánchez, 2015: 131-133).

53 ADM, Santisteban, 39-2, exps. 5 y 7.

54 Igual ocurrió con la de Malagón. Véase Sánchez, 2015: 133-139.

55 Más datos en Sánchez, 2015: 149-160.

56 Arana fue un leal servidor de la Casa pues defendió los archivos y todo el patrimonio ducal como si fuera suyo durante los difíciles años de la guerra de la Independencia (véase Sánchez, 2015: 152-167).

57 El Archivo Ducal de Medinaceli, en su conjunto, estaba entonces integrado en 42 secciones, con 3.864 legajos, 502 libros y 37 documentos sueltos, que se custodiaban en las 460 papeleras del depósito. 
Tabla 2. Disposición del fondo del marquesado de Malagón y otros bienes de la Casa en el Archivo Ducal de Medinaceli (1886)

\begin{tabular}{|c|c|c|c|c|}
\hline SIGNATURA & SERIES & $\begin{array}{c}\mathrm{N}^{\mathrm{O}} \\
\text { LEGAJOS }\end{array}$ & $\begin{array}{l}\text { No DOCS. } \\
\text { SUELTOS }\end{array}$ & $\begin{array}{c}\mathrm{N}^{\mathrm{o}} \\
\text { LIBROS }\end{array}$ \\
\hline Papelera $1^{\mathrm{a}}$ & Poderes & 1 & & \\
\hline Idem & Inventarios & & & 1 \\
\hline Papelera $2^{\mathrm{a}}$ & $\begin{array}{l}\text { Papeles referentes á este estado } \\
\text { (Leg. } 1 \text { á 9, } 11 \text { á 13, } 19 \text { y 20) }\end{array}$ & 14 & & \\
\hline Papelera $3^{a}$ & Idem (Leg. 10, 14 á 18 y 21 á 25) & 11 & & \\
\hline Papelera $4^{a}$ & $\begin{array}{l}\text { Reconocimientos de censos en } \\
\text { Fiñana }\end{array}$ & & & 8 \\
\hline Idem & Escrituras de censos en Fiñana & & & 3 \\
\hline Idem & Apeo, deslinde, tasación, etc. & & & 1 \\
\hline Papelera $5^{a}$ & —vacía — & & & \\
\hline Papelera $6^{\mathrm{a}}$ & $\begin{array}{l}\text { Papeles pertenecientes á } \\
\text { Paracuellos (Leg. 10 á 19) }\end{array}$ & 19 & & \\
\hline Papelera $7^{a}$ & $\begin{array}{l}\text { Fiñana: Hospital de San Juan } \\
\text { Bautista de Toledo (Leg. } 1^{\circ} \text { á 6º }\end{array}$ & 6 & & \\
\hline Papelera $8^{a}$ & Fiñana: Idem (Leg. $7^{\circ}$ ) & 1 & & \\
\hline Papelera 9a & —vacía - & & & \\
\hline Papelera 10 & $\begin{array}{c}\text { Papeles pertenecientes á Sevilla } \\
\text { (Leg. } 1^{\circ} \text { á } 6^{\circ}, 8^{\circ} \text { á } 14 \text { y uno sin } \\
\text { numeración) }\end{array}$ & 14 & & \\
\hline Papelera 11 & $\begin{array}{c}\text { Idem (Leg. 7, } 15 \text { á 17, } 19 \text { á } 25 \text { y } \\
\text { uno sin numerar) }\end{array}$ & 12 & & \\
\hline Papelera 12 & $\begin{array}{l}\text { Escrituras de reconocimiento de } \\
\text { censos, autos, etc. de Valencina }\end{array}$ & 1 & & \\
\hline Idem & Idem de Villanueva del Río & 1 & & \\
\hline Idem & Idem de Utrera & 1 & & \\
\hline
\end{tabular}

Fuente: ADM, Archivo Ducal. Leg. 14.

Para entonces ya estaba vigente en el archivo ducal el nuevo ciclo archivístico que nosotros denominamos de la "Desvinculación señorial"58, hoy mantenido en el depósito.

58 Se trata del período que arranca con la abolición de los mayorazgos y de los señoríos jurisdiccionales, que coincide con la entrada del régimen político del liberalismo en España, en el que la nobleza sufre una gran transformación que afectó también a sus archivos (véase Sánchez, 2017). En ese contexto, la sección Paracuellos quedó oculta dentro de la sección Medinaceli-Desvinculación, integrada en los legajos 180 a 186, hasta que procedimos el darle carácter independiente que hoy tiene durante nuestra etapa de director 
Así, hubo un cambio en cuanto al sistema de instalación documental, un reajuste de las secciones del archivo y una modificación los instrumentos de descripción, estableciéndose además los cauces para la futura archivación (Sánchez, 2014: 104-109).

En cuanto al modo de instalación documental, fueron sustituidas las antiguas papeleras del Archivo General de los Medinaceli por legajos -los mismos que los actuales-, que se colocaron en estanterías abiertas, con lo que se modificaba la tradicional reconditez y el carácter arcano que habían caracterizado a los fondos archivísticos durante el Antiguo Régimen por un sistema aperturista y perceptible. Este cambio se produjo a fines del siglo XIX y lo materializó el buen archivero Antonio Paz y Mélia. Entonces se mantuvo, como hoy, la sección Paracuellos, con 7 legajos, y quedó separada, como en origen, la principal de Malagón, con 30 legajos más. La estructura de la primera, que nos ocupa, se refleja en el cuadro de clasificación del fondo que aquí recogemos (tabla 3).

Tabla 3. Cuadro de clasificación final de la Sección Paracuellos

\section{GESTIÓN DE LA DOCUMENTACIÓN}

1.1. Apuntamientos: informes de los archiveros sobre diversas materias concernientes al señorío

2. DESCENDENCIA Y SUCESIÓN

2.1. Fundaciones y agregaciones de mayorazgos

3. PATRIMONIO

3.1. Títulos de dominio y jurisdicción

3.2. Apeos del término

3.3. Pastos

3.4. Tierras y dehesas (Belvis de Jarama, Valdemartibáñez, Majuelos de Rinconada, Jarama,

El Barco de Villanueva, Sotocastaños, Saceda, Palomarejo, Retama, Tabla del Río, Madrevieja, etc.)

3.5. Heredades (El Burrillo, Viñuelas, Cobeña...)

3.6. Tierras baldías

3.7. Molinos y otros bienes

3.8. Casas, tierras, olivares, viñas

3.9. Regalías señoriales

3.10. Tomas de posesión

4. PATRONATOS, CAPELLANÍAS, CURATOS Y PROVISIONES ECLESIÁSTICAS

4.1. Iglesia parroquial de Paracuellos

4.2. Convento franciscano de San Luis

4.3. Patronazgo de la provincia de San José, de la orden franciscana

4.4. Hospital de Paracuellos

5. OFICIOS Y DIGNIDADES

5.1. Nombramientos de oficiales del señorío

6. CONTABILIDAD

6.1. Cuentas y relaciones de rentas

6.2. Diezmos

6.3. Alcabalas y tercias

6.4. Censos

6.5. Martiniegas, mostrencos, portazgos, pecho de San Miguel y Rentillas

6.6. Penas de cámara

7. VARIOS

7.1. "Papeles inútiles": ejecutorias, etc.

Fuente: Elaboración propia

del Archivo Ducal. 
Así estructurada es como se ha transmitido la documentación del señorío de Paracuellos de Jarama hasta nuestros días, que arranca del año 1175.

\section{CONCLUSIONES}

El antiguo fondo documental del señorío paracuellense se compone de varios centenares de diplomas, custodiados hoy en su mayor parte en los 7 legajos referidos del Archivo Ducal, más algunas piezas sueltas o pequeñas series distribuidas en otras secciones del mismo depósito -también de estados señoriales con los que los Pardo-Tavera tuvieron relación parental- como las de Santisteban, Villalonso y Castellar, además de en la miscelánea denominada Archivo Histórico y en las facticias Privilegios rodados y Mapas y Planos. Obviamente, el complemento natural de este fondo de Paracuellos se encuentra en la sección Malagón del mismo archivo.

A fines del siglo XIX y en los comienzos del XX, con el citado archivero Paz y Mélia, pasaron a formar parte de dicha miscelánea histórica alguna correspondencia real y particular de varios señores de Paracuellos y marqueses de Malagón, junto a un grupo de reales cédulas y provisiones de concesión de mercedes y otros privilegios, además de abundante correspondencia de valija diplomática de algunos señores, condes y duques ${ }^{59}$, aparte otra correspondencia y documentación sobre funciones gubernativas desempeñadas por algunos de estos nobles en Italia, Perú, etc. durante la Edad Moderna ${ }^{60}$. Parte de esta documentación ya ha sido dada a conocer, pero solo en aspectos muy parciales ${ }^{61}$, estando pendiente una obra de conjunto de este señorío madrileño.

De la documentación paracuellense, el Archivo de la Casa Ducal de Medinaceli conserva como instrumento de descripción útil aquel antiguo inventario de Terán denominado Libro del Partido de Paracuellos, que sustituyó al anterior de Brochero, ambos del siglo XVIII, refrendo de cuando se organizó la mayor parte de la documentación del señorío, junto con las fichas catalográficas realizadas por Paz y Mélia a fines del siglo XIX que aún se conservan. El propio sistema orgánico que se estableció en este fondo -como en el resto del archivo- con la documentación, pieza a pieza, descrita en las carpetillas o "guardas" de cada documento, realizada por los distintos archiveros, ayuda a la identificación y conocimiento del contenido de toda la documentación del señorío.

Sirva, además, de contribución al conocimiento de este antiguo fondo la guía que incluimos nosotros aquí (tabla 4), con descripción de sus series, las fechas extremas y la signatura de localización de los documentos, como aportación para quien necesite la consulta de esta documentación madrileña que forma parte del Archivo General de la Fundación Casa Ducal de Medinaceli.

59 De los condes Manuel y Antonio de Benavides, I duque y II duque de Santisteban del Puerto, respectivamente. Véase ADM, Archivo Histórico, leg. 80 ns. 49-74.

60 ADM, Archivo Histórico, leg 74, ramos 10 a 15, y leg. 75, ramos 1 a 40, más leg. 80, ramo 24, docs. 1 a 28.

61 Por ejemplo, del conde que fue virrey del Perú y otros ya referidos. 
Tabla 4. Guía de la Sección Paracuellos del Archivo Ducal de Medinaceli

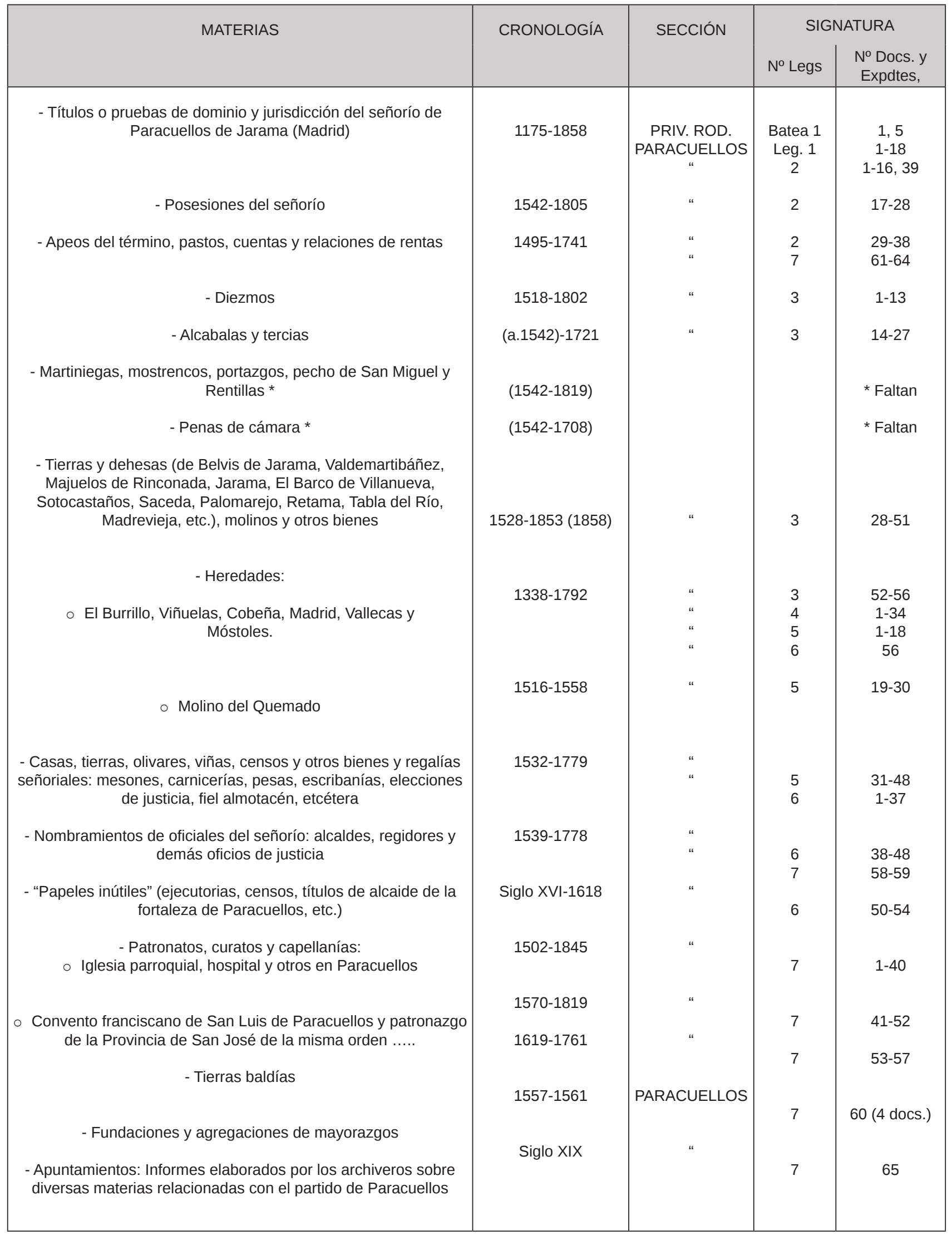

Fuente: Inventarios del ADM. Elaboración propia 


\section{BIBLIOGRAFÍA}

Campo Real, F. del (1997), Malagón: Un señorío en el Campo de Calatrava, Ciudad Real, Diputación Provincial.

- (2000), "Venta de la encomienda calatrava de Malagón al Mariscal de Castilla don Antonio Ares Pardo de Saavedra", en J. López Salazar (coord.), Las órdenes militares en la Península Ibérica, 2: Edad Moderna, Cuenca, Ediciones de la Universidad de. Castilla-La Mancha, pp. 1795-1816.

Cepeda Adán, J. (1980), "Desamortización de tierras de las Órdenes Militares en el reinado de Carlos I", Hispania, 146, 487-528.

Corchado Soriano, M. (1982), El Campo de Calatrava. Los Pueblos, Ciudad Real, Diputación Provincial - Instituto de Estudios Manchegos.

- (1984), La orden de Calatrava y su campo, Ciudad Real, Diputación Provincial Instituto de Estudios Manchegos.

Fernández de Bethencourt, F. (1920), Historia genealógica y heráldica de la Monarquía Española, Casa Real y Grandes de España, tomo X, Madrid, Tipografía de Jaime Ratés.

Franco Silva, A. (2001), "La desamortización de bienes de órdenes militares en la época de Carlos V: Ios casos de Paracuellos y Malagón", en J. L. Castellano y F. Sánchez-Montes (coords.), Carlos V, europeísmo y universalidad: población, economía y sociedad, vol. 4, Madrid, Sociedad Estatal para la Conmemoración de los Centenarios de Felipe II y Carlos V, 237-274.

García del Arroyo de Vázquez de Parga, C. (s.a. [1946]), Privilegios reales de la orden de Santiago en la Edad Media. Catálogo existente en el Archivo Histórico Nacional. Madrid, Imp. Blass.

González, J. (1960), El reino de Castilla en la época de Alfonso VIII, 3 vols., Madrid, CSIC. Jara, A. (1914), Albornoz en Castilla, Madrid, Librería de Fernando Fe.

Lafuente Urién, A. (2010), "Los archivos nobiliarios, formación y conservación", en Estudios sobre señorío y feudalismo. Homenaje a Julio Valdeón, Zaragoza, Institución Fernando el Católico (CSIC), 27-75.

López Agurleta, J. (1719), Bullarium Equestri Ordinis Sant lacobi de Spatha..., Madrid, ex Typographia loannis de Aritzia.

Melero Cabañas, D. (2005), Ciudad Real: tierra de Castillos, Ciudad Real, Imprenta Provincial.

Moxó, S. de (1961), "Las Desamortizaciones eclesiásticas del siglo XVI", Anuario de Historia del Derecho Español, XXXI, 327-361.

Otte, E. (2003), "Diego Caballero, funcionario de la Casa de la Contratación", en A. Acosta Rodríguez (coord.), La Casa de la Contratación y la navegación entre España y las Indias, Sevilla, CSIC \& Universidad de Sevilla, 315-339.

Porras Arboledas, P. A. (1997), La Orden de Santiago en el siglo XV. La Provincia de Castilla, Madrid, Dykinson.

Rivera Garretas, M. (1985), La encomienda, el priorato y la villa de Uclés en la Edad Media (1174-1310). Formación de un señorío de la Orden de Santiago, Madrid, CSIC.

Romero Tallafigo, M., Rodríguez Liáñez, L. y Sánchez González, A. (2003), Arte de leer escrituras antiguas. Paleografía de lectura, Huelva, Universidad de Huelva.

Salazar y Castro, L. de (1949), Los comendadores de la Orden de Santiago, 2 tomos, Madrid, Patronato de la Biblioteca Nacional, I (Castilla), 268-277 (Paracuellos).

Salazar y Mendoza, P. de (1603), Chronico de el Cardenal Don luan Tauera, arzobispo de Toledo. Toledo, Pedro Rodríguez Impresor.

Sánchez González, A. (2012), "Los privilegios rodados originales del Archivo Ducal de 
Medinaceli: I. Alfonso VIII de Castilla (1158-1214)", En la España Medieval, 35, 367412.

- (2014), El Archivo de los Adelantados de Andalucía (Casa de Alcalá), Sevilla, Universidad de Sevilla.

- (2015), El Archivo de los Caudillos del reino de Jaén (Casa de Santisteban del Puerto), Jaén, Diputación Provincial de Jaén - Instituto de Estudios Giennenses.

- (2016), "Heráldica episcopal hispana: la capilla de San Pedro de la Catedral de Sevilla y sus vestigios emblemáticos", Tabularium Edit, 3, 198-224.

- (2017) "Nobleza, archivo y mayorazgo", en A. Suárez González (coord.), Escritura y sociedad: la nobleza, Santiago de Compostela, Universidad, 329-342.

- (en prensa), "Los archivos del Cardenal: El fondo documental sevillano de D. Juan Pardo Tavera".

Segura Graiño, C. (1982), "La orden militar de Santiago en la provincia de Madrid en la Baja Edad Media: las encomiendas de la ribera del Tajo", Anales del Instituto de Estudios Madrileños, XIX, 349-361.

Urquiaga Cela, D. (2000), "Las Órdenes Militares en el valle medio oriental del Tajo (siglos XII-XVI): el fenómeno de la desolación de núcleos de población rural", en R. Izquierdo Benito y F. Ruiz Gómez (coords.), Las Órdenes Militares en la Península Ibérica, Cuenca, Ediciones de la Universidad de Castilla-La Mancha, I, 193-214. 